\title{
A Sequential Input-Output Framework to Analyze the Economic and Environmental Implications of Energy Policies: Gas Taxes and Fuel Subsidies
}

\author{
Jun-Ki Choi 1,2,", Bhavik R. Bakshi ${ }^{3}$, Klaus Hubacek ${ }^{4}$, and Jordan Nader² \\ ${ }^{1}$ Renewable and Clean Energy Graduate Program, University of Dayton, Dayton OH 45469 \\ 2 Department of Mechanical Engineering, University of Dayton, Dayton OH 45469 \\ 3 William G. Lowrie Department of Chemical and Biomolecular Engineering, Ohio State University, \\ Columbus, OH 43210 \\ ${ }^{4}$ Department of Geographical Sciences, University of Maryland, College Park, MD 20742 \\ * corresponding author: jchoi1@udayton.edu
}

\begin{abstract}
A novel generic sequential input-output framework is developed to model the economywide changes in resource consumption and environmental emissions as a result of combined applied energy policies, e.g. taxes for non-renewables and subsidies for renewables. Many input-output analyses are based on a single period analysis. However, in the case of analyzing the effects of multiple policy interventions over time, the input-output table reflecting the state of the economy before the energy policy was introduced cannot be used for analyzing the economic effects of another policy intervention in the next time period since the monetary and physical transaction of commodities have already been affected. To show the efficacy of the proposed method, a case study is developed that introduced a gasoline tax and earmarks the revenues to subsidize biofuel production in the subsequent time period in the United States. In order to assess the change of environmental indicators after sequential policy interventions, Ecologically-based Life Cycle Analysis (ECO-LCA) inventories which include data on resource consumption, emissions, ecosystem goods and services related to the U.S. economic sectors are adopted. The environmentally extended input-output framework is ideally suited to model the interlinkages between a range for environmental indicators and detailed structural economic information at the sector level for the analysis of energy policies. The proposed framework can be utilized as a tool for leveraging the energy and environmental policy trade-off decisions which consider the impacts to resource consumption and environmental emissions. Our results show that, if a share of the gasoline tax revenue is reinvested to subsidize biofuel production, economy wide resource consumptions and emissions from the fossil fuel related supply chains will decrease. However, ecosystem goods and services such as soil erosion, water consumption for agricultural and livestock, cropland, nitrogen deposition along with the emissions such as nitrous oxide and ammonia will increase in short term as a consequence of the price drop and the increased demand for biofuels. This emphasizes the importance of focusing on a wide range of environmental outcomes and unintended side effects when introducing a specific environmental policy.
\end{abstract}

Keywords: sequential economic input-output analysis, gasoline tax, alternative fuel subsidies, resource consumptions, emissions, ecosystem goods and services. 


\section{Introduction}

Imposing a specific monetary charge to a commodity has long been viewed as a theoretically attractive tool to discourage environmental harm, conserve energy, and for certain countries to reduce dependence on imported oil. Placing a tax on fossil fuels may make alternative fuels more attractive, and creates an incentive for manufacturers and consumers to choose more fuel-efficient products and processes. A number of policy studies consider the change of commodity prices through an energy tax or subsidy merely as an additional social cost directly caused by certain energy policies (i.e. gasoline tax, biosubsidies, etc.). Doing so fails to capture system-wide effects, i.e. the cost accrued throughout the entire supply chain through consumption of resources and factors whose prices are also affected by the policies indirectly. In this paper, we model the environmental effects and trade-offs arising from the introduction of a gasoline tax coupled with subsidies for biofuels based on the earmarked tax revenues for the US. We do by developing a novel generic sequential input-output framework to assess the direct and indirect economic and environmental impacts of energy policies by considering both monetary and physical changes of economic goods and services.

There are three major contributions of this work. First, the proposed methodology adjusts the baseline input-output table by updating the effect of a policy. The amended input-output table is then used to assess the economic and environmental impacts after reallocating the portion of the fuel tax revenue to subsidize the biofuel production. Therefore, the advantage of the proposed methodology come into play when a modeler assesses the sequential policies. This analysis differs with the case of applying combined fuel tax and bio subsidy at a single period where the availability of funding for subsidies are automatically assumed. Secondly, this study utilizes partially available information about price elasticities of demand to model consumer behavior in the short-run in the inputoutput analysis context. Thirdly, the proposed framework will be able to model the changes in resource consumption, environmental emissions, ecosystem goods and services upon various combined policy interventions. Life cycle resource consumption and emission data for the U.S. economic sectors are adopted from the ECO-LCA [1]. ECO-LCA is taking into account not only resource consumption and emissions but also ecosystem services like soil erosion, pollination, flood prevention and cropland coupled with the economic sectors in the United States [2-4]. Ecosystem services in the tool is classified into four areas: Supporting services (soil, pollination, sunlight, hydro, geothermal, wind, etc.), regulating services (flood protection, disease regulation, carbon sequestration, etc.), provisioning services (fuels, ores, water, timber, cropland, etc.), and cultural services (spiritual and recreational benefits, etc.) [5, 6]. It provides a coarse estimation of how different products might compare to one another and provide broader environmental implications of economic products. Since all the economic activities are correlated, these environmental loads are changing directly and indirectly based on different policies. In this paper, we illustrate the changes in resource consumption, ecosystem goods and services, and emissions. Comprehensive data can be found from the ECO-LCA.

\section{Background}

In the US, the first gasoline tax was created in 1919 in Oregon with the other 47 states adding a gasoline tax by the end of 1929. In 1932, the U.S. Federal Government 
implemented the first federal gasoline tax at $\$ 0.01 /$ gallon. This tax has risen periodically until 1997, since when it has remained at $\$ 0.184 /$ gal [7]. Incorporating state gasoline taxes, the US national fuel tax is $\$ 0.403 /$ gal on average. [8]. According to the U.S. Energy Information Administration (EIA), U.S. motor gasoline and diesel fuel usage in 2014 was responsible for $28 \%$ of energy related $\mathrm{CO}_{2}$ emissions. Each gallon of gasoline consumed emits roughly 19.6 pounds of $\mathrm{CO}_{2}$ and the EIA estimates that 1,075 million metric tons of $\mathrm{CO}_{2}$ were emitted in 2014 as a result of gasoline consumption [9]. Recognizing the benefits of decreased $\mathrm{CO}_{2}$ emissions to mitigate climate change, it seems advantageous to increase fossil fuel taxes further to incentivize consumers to choose other propellant sources (i.e. electric, bio-fuel, hydrogen fuel cell, compressed natural gas, etc.). There are numerous factors to consider in the economics of increasing fuel taxes. For example, there are competing economic interests at stake when considering raising the fuel tax versus maintaining or reducing the fuel tax [10]. In addition, there is a distributional effect. Recognizing that the United States is in the bottom third of OECD countries for population density and how this impacts private vehicle ownership will be a factor in accounting for the impacts of raising fuel taxes on different sectors and households. A number of studies explored whether pursuing increased taxes on vehicles would be equally effective in reducing $\mathrm{CO}_{2}$ emissions as increasing fuel taxes. However, they found that pursuing taxes on vehicles is less effective at reducing long-term fuel consumption than increasing fuel excise taxes to change consumer behavior [11]. Similarly, a study focusing on the $\mathrm{CO}_{2}$ emissions of urban transportation found that increasing fuel taxes by $\$ 0.11 /$ gallon over a ten year period would result in a $13.2 \%$ reduction in the number of vehicles operated in an urban area when compared against a baseline growth model [12], and that increasing the fuel tax was more effective at reducing fuel consumption, and thus $\mathrm{CO}_{2}$ emissions, than making public transportation free or improving support for motorcycles. The degree to which fuel taxes should be increased to result in significant changes in long run fuel consumption requires some guidance for policy makers [13].

In addition to the impacts of increased fuel taxes, there is growing concern about the impacts of increased reliance on alternative transportation fuels. Searchinger et al. [14] suggest that far from reducing carbon emissions, bioethanol that results from crop switching could represent a 52 year payback and an increase in $\mathrm{CO}_{2}$ emissions by $50 \%$ over 30 years. This is in part due to utilizing commodities that were previously for food consumption and now have switched to fuel, resulting in increased food costs, and also in part due to land use changes that occur from farmers changing from crop or timber production to biofuels. Delucchi [15] found through life cycle analysis that the production of corn ethanol did not result in GHG emissions significantly lower than that of gasoline, whereas in the case of cellulose ethanol, the GHG emissions were $50 \%$ of the emissions of gasoline. Fully accounting for the life cycle costs of a commodity is necessary for the market to accurately price goods and concerns about biofuel production expansion should be heeded lest they aggravate climate change further. Some studies show that even when the highly debated land use change GHG emissions are included, switching to biofuels helps to significantly increase the reductions in energy use and GHG emissions [16, 17]. The additional revenue that can be reaped from an increased fuel tax can partly be earmarked to increase research into new strains of transportation fuels to minimize the need to expand land use. For example, with further research aquatic microbial oxygenic photoautotrophs (AMOPs) present the opportunity of higher efficiency solar collection, to 
use less or no land, and can provide secondary uses that are not otherwise possible with fossil fuels [18]. While biofuels present great promise, a measured approach is warranted to reasonably account for the indirect consequences.

Input-output analysis is a macro-economic tool utilized for assessing the overall economy-wide impacts of producer and consumer activities. Input-output analysis has been widely used for various applications such as economic, environmental, and energy modeling to determine the total (i.e. direct, indirect, and induced) monetary or physical transactions involved in the production of final products [19]. One of the major benefits of input-output analysis is that it provides a snap-shot of an economy at a specific period with readily available empirical data [20]. Input-output analysis can be categorized based on the temporal application, monetary/physical accounting, and the application of supply and demand side methodological perspectives. In terms of the temporal application, inputoutput analyses can be categorized as either short-run impact analysis or long-run projections or forecasting [21]. Whereas short-run analysis assumes no change in production technology, however, as the period of projection gets longer, modeling needs to consider factors such as change of production technology [22, 23] and the corresponding change of consumer demand [24,25] induced by a variation of commodity prices. In terms of accounting methodology, modeling efforts have been performed with either Physical Input-Output Transaction Table (PIOT), Monetary Input-Output Transaction Table (MIOT)[26] or mixed units [27], - for example, energy flows in the economy are traced in physical energy units and non-energy flows in dollars [28-30]. All monetary transaction values in the input-output analyses are composed of two components: price and quantity $[21,31]$. In terms of the mathematical modeling point of view there are two pioneering models: Leontief quantity model and price model.

In most of the single period input-output analyses, monetary change in final demand implicitly implies the change of the physical amount of goods and services while prices are not affected. However, in multiple period analysis where the effect of a multiple sequential scenarios is considered, effects of price variation in goods and services should be considered. If a price of commodity changes, the monetary value of transactions between economic sectors in the input-output table will alter in the next period even though the physical value of transactions remains the same since the monetary transaction consists with the price and the quantity. It is crucial to discern the fundamental causes of changes in monetary values, which consist of price and quantity components. Physical accounting can avoid the disturbance of price in transactions between sectors but Physical Input Output Tables are not very common [32] but are now part of the standard compilation procedure proposed by the new UN Handbook on Supply, Use and Input-Output Tables [33]. Combined use of both monetary and physical accountings is required to analyze the effect of scenarios in consecutive periods.

\section{Methodology}

\subsection{Basic models}

Leontief input-output quantity model $[19,34]$ shown in Eq.(1) takes the changes in the final demand ( $\mathbf{y})$ as exogenous, and calculates the change in gross production (x) which is required to ensure that supply equals demand for each sector. Direct requirement matrix 
(A) consists of dollar inputs from industry $i$ needed to product $\$ 1$ output from industry $j$ with the given monetary transaction table.

$$
\Delta \mathbf{x}=(\mathbf{I}-\mathbf{A})^{-1} \Delta \mathbf{y}
$$

A Leontief price model $[35,36]$ is considered to be a supply side model as shown in Eq. (2). It captures the percentage change of commodity price by the change of exogenous payment (i.e. value added). A gasoline tax or bio-fuel subsidy can be viewed as an exogenous increase in the value added $\left(\Delta \mathbf{v}^{\%}\right)$ of products as will be shown in the case study section. It takes the changes in the prices of the primary cost factors as exogenous, and computes the product prices which are necessary for the total costs to equal the total revenues for each sector.

$$
\Delta \mathbf{p}^{\%}=\left(\mathbf{I}-\mathbf{A}^{\prime}\right)^{-1} \Delta \mathbf{k}
$$

Here $\Delta \mathbf{p}^{\%}$ is the percentage price change and $\Delta \mathbf{k}=\Delta \mathbf{v}^{\%} \mathbf{v}(\hat{\mathbf{x}})^{-1}$. The resulting environmental loads are calculated by following Eq. (3)

$$
\Delta \mathbf{e}=(\mathbf{R}) \Delta \mathbf{x}
$$

, where, $\mathbf{e}$ is the physical amount of the environmental loads (emissions or resource consumptions) matrix and $\mathbf{R}$ is the matrix of physical environmental loads per dollar production of $\mathbf{n}$ sectors $[21,37,38]$. The vector $\Delta \mathbf{x}$ can be derived from Eq. (1).

Using these basic input/output models, we propose a framework for looking at the multi-sector effects of environmental policy changes. Particularly, we consider the case of a policy-maker imposing the external social costs of production (or consumption) of energy commodity in the form of a tax/subsidy. In micro-level economic analyses, the effects of this exogenous tax/subsidy are analyzed in the market of interest. But, for large changes in sectoral level prices, or policies affecting most if not all sectors (like a gasoline tax and biofuel subsidies), the imposition of the tax/subsidy may change the relative prices of commodities in all sectors, thereby changing the relative demand for commodities from all sectors. In order to integrate the effect of changes in consumer behavior, we adapt the standard models to allow for changes in quantity demanded in reaction to exogenous price shock. It is important to note that we are not attempting to model full general equilibrium adjustments [39] because the emphasis of this study is for the short-term combined effect of the sequential gasoline tax and bio-fuel subsidies where the production technology is fixed over a relatively short period of time. It is noted that the proposed methodology focus on utilizing the tax revenue from one period to support the production of bio-fuel in the next period. Although the proposed methodology can be utilized to analyze the same period combined policy effect, the case study shows sequential analysis (i.e. levy gas tax first and use certain portion of revenue for subsidizing the biofuel related sectors).

\subsection{Proposed framework}

Fig. 1 represents the proposed framework. Numeric subscript indicates the subsequent change of price, quantity, and emissions for whole economic sectors considered. In terms of a temporal aspect of the modeling, we consider following steps of changes: 1) the baseline economy where gasoline tax is levied on the current economy, 2) the first step where the commodities' price change after the gasoline tax levied on the gas production and related 
supply chains, 3) the second step where the consumer behavior varies and the economywide emission changes because of the reduced total productions 4) the third and fourth steps capture the economic and environmental effects of biofuel subsidies after certain portion of the gasoline tax revenues are invested to the bio-fuel production supply chains. The main purpose of the proposed sequential methodology is to forecast the short term effect of one or multiple policies based on the available input-output data. Therefore our methodology is not affected by the availability of time series IO tables. Following sections details each step.

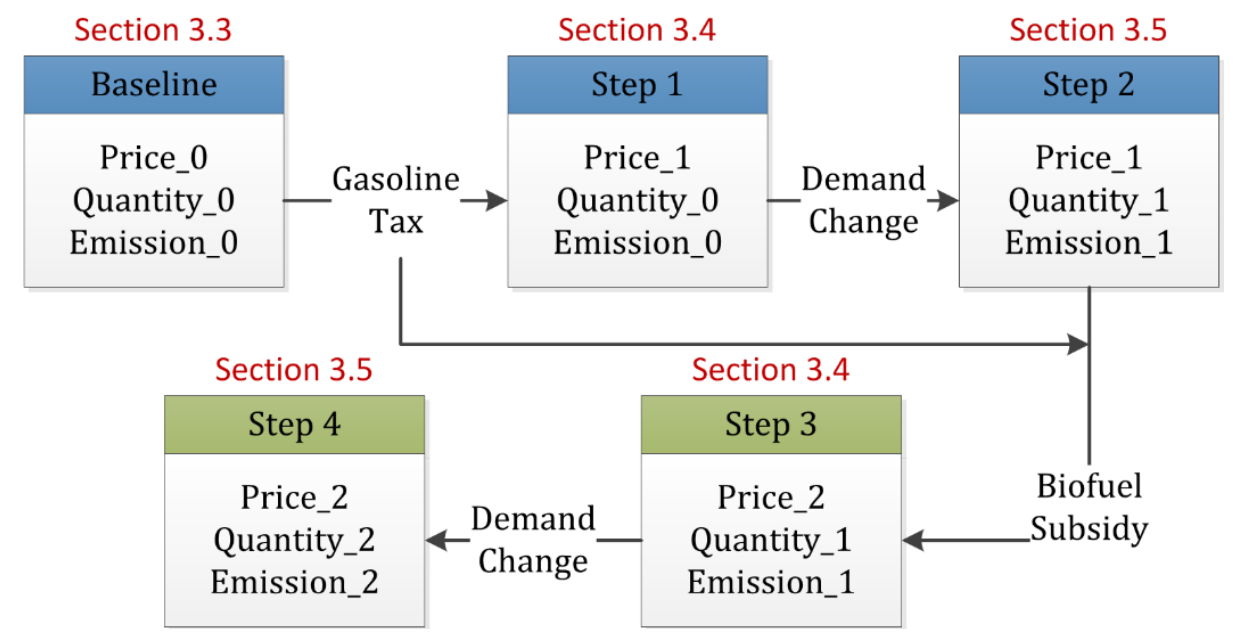

Fig. 1. Process to capture the economic/ environmental effects of the combined policy (section numbers are indicated above each box, section 3.6 applies to every step).

\subsection{Base period economy (baseline)}

The structure of the monetary transactions of an economy is the starting point of the analysis and the simplified monetary input-output table (MIOT) in this period showed in Fig. 2. Subscripts " 0 " indicates the base period before price and quantity are influenced by policy intervention and/or consumer demand changes. $\mathbf{Z}$ is the $\mathrm{n} \times \mathrm{n}$ sectors inter-industry matrix, $\mathbf{y}$ is the final demand vector, $\mathbf{x}$ is the total output vectors, and $\mathbf{v}$ is the value added components of monetary input-output table respectively. With the information about base price of commodities (i.e. price vector, $\mathbf{p}_{0}$ ), the physical transactions of commodities can be determined. $\mathbf{S}$ is the physical inter-industry matrix, $\mathbf{f}$ is the final demand column vector form in physical values, $\mathbf{q}$ is a column vector of total industry output in physical values. It is assumed that there is a one-to-one correspondence between the unit price and the products of the corresponding sector for this analysis (i.e. homogenous price). Therefore a unique sector price is the requirement for a quantity model based on a MIOT[26]. For a physical input output table (PIOT), there is no reason to perform the column analysis (i.e. value added vectors and total input vectors) since the physical units of input from $i$ sectors to $j$ sectors are different. 


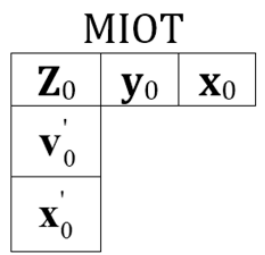

\begin{tabular}{|l|l|l|}
\multicolumn{3}{c}{ PIOT } \\
\hline $\mathbf{S}_{0}$ & $\mathbf{f}_{0}$ & $\mathbf{q}_{0}$ \\
\hline
\end{tabular}

Fig. 2. Monetary and physical Input-output tables in the base period.

\subsection{Calibrating the effect of price change (models for steps $1 \& 3$ )}

In an input-output table, various factors are included as part of the value added components, such as depreciation of capital, labor cost, and taxes and subsidies. Additional costs on these economic factors will directly increase the price of a commodity in the economic sector. In addition, price of commodities produced/serviced by other economic sectors will change indirectly. Suppose that a certain amount of gasoline tax is levied, then the new value added vector in the intermediate term can be determined by Eq. (4). It is the summation of the original value added at the base period $\left(\mathbf{v}_{0}\right)$ and the amount of the additional tax levied to the relevant economic sectors.

$$
\mathbf{v}_{\mathbf{1}}=\mathbf{v}_{0}+\left(\boldsymbol{\tau}_{\mathbf{i}}\right) \mathbf{s}_{\mathrm{f}}
$$

, where $\boldsymbol{\tau}_{i}$ is a specific amount of gasoline tax levied on the sectors $i$ and $\boldsymbol{s}_{\boldsymbol{f}}$ is a vector illustrating the physical amount of gasoline consumed by each individual sector of the economy.

Leontief price model takes the changes in the prices of the primary cost factors as exogenous, and computes the commodity prices which are necessary for the total costs to equal the total revenues for each sector. The price model in Eq. (2) estimates the percentage change in prices $\left(\Delta \mathbf{p}^{\%}\right)$. With the information of the percentage price change and original prices, the vector for new prices of commodities $\left(\mathbf{p}_{\mathbf{1}}\right)$ can be estimated. After the price of commodities changes, the monetary value of final demand should be adjusted with the new price to be used for the next step of the sequential input-output analysis. The balanced final demand vector can be found in various ways. For example, in Eq. (5) we use the price vector and the previous final demand vector. It reflects the fact that change of $\mathbf{y}_{\mathbf{1}}$ is only caused by the chance in prices.

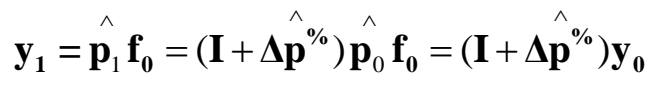

Monetary transactions of the input-output table in this intermediate period (i.e. subscript "1") will be balanced based on the change of prices of all commodities. Fig. 3 confirms that the PIOT values are exactly the same as the previous period's PIOT value in Fig. 2 since physical values are not changed.

MIOT

\begin{tabular}{|c|l|l|}
\hline $\mathbf{Z}_{1}$ & $\mathbf{y}_{1}$ & $\mathbf{x}_{1}$ \\
\cline { 1 - 1 } $\mathbf{v}_{1}{ }^{\prime}$ & \multicolumn{2}{|l}{} \\
\cline { 1 - 1 } $\mathbf{x}_{1}{ }^{\prime}$ & & \\
\cline { 1 - 1 } & &
\end{tabular}

PIOT

\begin{tabular}{|l|l|l|}
\hline $\mathbf{S}_{1}$ & $\mathbf{f}_{1}$ & $\mathbf{q}_{1}$ \\
\hline
\end{tabular}


Fig. 3. Balanced monetary and physical input-output tables in the first step.

Therefore, the physical input coefficient matrix ( $\mathbf{C}$ - inputs necessary for production of commodities, sometimes referred to as "production recipe") does not change in period 1 compared to the base period. This relationship can be explained by Eq. (6) as well. It implies that the physical production technology $\left(\mathrm{C}_{\mathrm{ij}}\right)$ has not been changed after additional value added costs (i.e. gasoline tax) are imposed. Therefore, this verifies the fact that the changed values in the new MIOT are solely caused by the changes in relative prices. The price model indicates that the physical production recipe does not change with a perturbation of value added in the MIOT. The aggregated dollar value in a MIOT (which is the product of price times a physical quantity) is only affected by a change of the price component. In our methodology, we did not introduce a new technology to the economy in the short run).

$$
\left(A_{i j}\right)_{1}=\frac{\left(p_{i}\right)_{1}\left(s_{i j}\right)_{0}}{\left(p_{j}\right)_{1}\left(q_{j}\right)_{0}}=\left(C_{i j}\right)_{0}\left(\frac{p_{i}}{p_{j}}\right)_{1}
$$

\subsection{Calibrating the effect of consumer demand change (models for steps $2 \& 4$ )}

Even in the short term, consumer may change the consumption pattern of those commodities affected by price changes. In order to integrate the effect of the price change to consumer behavior, the price elasticity of demand is adopted. Price elasticity of demand is the ratio of the change in the physical amount of demand to the corresponding change in commodity prices. Following steps illustrate the process for incorporating the economic effect of the physical amount of consumption as a response to the price change of commodities. First, given historical price elasticity of demand for each commodity $i\left(\mathbf{e}_{d, i}\right)$, the potential change of physical amount of final demand $\left(\mathbf{f}_{2}\right)$ can be estimated with Eq. (7). Note that $\mathbf{f}_{0}$ is equal to $\mathbf{f}_{1}$ since physical values of final demand have not been changed in the first period.

$$
\mathbf{e}_{\mathrm{d} . i}=-\left(\frac{\Delta f / f}{\Delta p / p}\right)=\frac{\left[\left(\mathbf{f}_{2}-\mathbf{f}_{0}\right) / \mathbf{f}_{0}\right]}{\Delta \mathbf{p}^{\%}}
$$

The change in physical demand of commodities influence a total economy system. New monetary value of the final demand vector in the new period, $\mathbf{y}_{2}$ now becomes the product of the new price $\left(\mathbf{p}_{1}\right)$ and new physical quantities $\left(\mathbf{f}_{2}\right)$ as shown in the Eq. (8).

$$
\mathbf{y}_{\mathbf{2}}=\hat{\mathbf{p}_{1}} \mathbf{f}_{2}=\left(\mathbf{I}+\Delta \hat{\mathbf{p}}^{\%}\right) \hat{\mathbf{p}_{\mathbf{0}}} \mathbf{f}_{2}
$$

where,

$$
\mathbf{f}_{2}=\left(\mathbf{I}-\hat{\Delta \mathbf{p}^{\%}} \hat{\mathbf{e}_{\mathbf{d}, \mathbf{i}}}\right) \mathbf{f}_{0}
$$

New monetary value of total production, $\mathbf{x}_{2}$ can be evaluated by the Leontief quantity model in Eq. (1). The Leontief model takes the changes in the final demand as exogenous, 
and calculates the change in gross production which is required to ensure that supply equals demand for each sector.

$$
\mathbf{x}_{2}=\left(\mathbf{I}-\mathbf{A}_{1}\right)^{-\mathbf{1}} \mathbf{y}_{2}
$$

New balanced monetary inter-industry transaction matrix $\mathbf{Z}_{2}$ is calculated with by premultiplying the fixed input coefficient matrix ( $\left.\mathbf{A}_{\mathbf{1}}\right)$ with the new $\mathbf{X}_{\mathbf{2}}$ as in Eq. (11).

$$
\mathbf{Z}_{2}=\mathbf{A}_{1}\left(\mathbf{x}_{2}\right)
$$

Fig. 4 shows that all changes are now purely caused by the change of the physical amount of commodity demanded as a response to the price change in the previous period.

$$
\begin{aligned}
& \text { MIOT } \\
& \begin{array}{|l|l|l|l|l|l|l|l|}
\hline \mathbf{Z}_{2} & \mathbf{y}_{2} & \mathbf{x}_{2}
\end{array} \\
& \hline
\end{aligned}
$$

Fig. 4. Balanced Monetary and Physical Input-output tables in the second period.

As a summary, Eqs. (12) and (13) captures the change of total economic production influenced by the various economic perturbations occurring in the one round of the sequential periods (steps).

where,

$$
\Delta \mathbf{x}_{\text {sequence }}=\left(\mathbf{I}-\mathbf{A}_{1}\right)^{-1} \Delta \mathbf{y}_{\text {sequence }}
$$

$$
\Delta \mathbf{y}_{\text {sequence }}=\mathbf{y}_{2}-\mathbf{y}_{1}=\left[-\left(\mathbf{I}+\Delta \hat{\mathbf{p}^{\%}}\right) \Delta \hat{p}^{\%} \hat{\mathbf{e}}_{\mathbf{d}, i}\right] \mathbf{y}_{\mathbf{0}}
$$

\subsection{Change of resource consumption and emission}

The amount of environmental loads in each period can be calculated by the Eq. (3) shown in the previous section. Life cycle resource consumption and emission data for the U.S. economic sectors are adopted from the ECO-LCA [1]. In this paper, we illustrate the percentile changes of few resource consumption, ecosystem goods and services, and emissions resulting from the changes in production of all economic sector's goods and services. Comprehensive data can be found from the ECO-LCA.

\section{Application of sequentially combined gas tax and bio-subsidy scenario}

As mentioned in the previous section, our starting point is the introduction of a fossil fuel tax to support the biofuel sector. Although, we can test the effect of applying two policies at the same period, in this case study, we illustrate the combined economic and environmental impacts of two sequential policies. Generally, a fuel tax is levied on the sale of gasoline utilized for transportation. Typically, diesel fuels are taxed at a lower rate. In the United States, fuel taxes vary by state. For example, in first quarter of 2008, the average 
state gasoline tax was 28.6 cents per gallon and 18.4 cents per gallon federal tax is added which makes the total 47 cents per gallon $(12.4 \mathrm{q} / \mathrm{L})$. For diesel, the average state tax is 29.2 cents per gallon plus an additional 24.4 cents per gallon federal tax making the total 53.6 cents US per gallon (14.2 $\$ / \mathrm{L})[40]$.

\subsection{Effects after gasoline tax}

In this case study, initially, 25cents/gallon of petroleum-based fuels are levied on transportation sectors in the 2002 US economic benchmark input-output table. The rationale of selecting this hypothetical amount is to illustrate the economic ripple effect of this additional amount of petroleum-based tax which is similar to the amount of the average state tax for both gasoline and diesel fuels. Decision makers can test any specific numbers with the proposed general framework. Physical amount of the fuels is estimated by dividing the monetary transaction from petroleum refineries to each transportation sector in the input-output table by the average spot price (i.e. $\$ 1.87$ / gallon of petroleum in year 2002). The physical amount of petroleum fuel consumed by each transportation sector is multiplied by the amount of carbon price per gallon levied. Eq. (4) is utilized to capture the increased amount of cost for transportation which are resulted from the carbon price levied on all transportation sectors in the North American Industrial Classification System (i.e. air- 481000, rail-482000, water-483000, truck-484000, transit and ground passenger-485000, pipeline-486000 scenic and sightseeing transportation and support activities for transportation- 48A000, Couriers and messangers-492000). Although some specific scenario can be considered (i.e. the case of airplanes use biofuels with kerosene, or trains be exempt from tax), it is out of our scope and we do not consider any of those effects in this illustrative case study. Eq. (5) is utilized to capture the economy-wide percentage price changes expected for all goods and services incurred from the increased price of transportation fuel in the U.S. Fig. 5 illustrates the percentage price increase resulting from the applied fuel tax. The blue portion of the bars indicates the percentage price increased by the direct tax dollars levied to the transportation sectors, the green and the red portions of bars indicate the price of other commodities increased by direct and indirect use of the transportation services throughout the inter-industrial economic activities. It shows that not only the price of transportation sectors increased directly but also the price of all goods and services of other economic sectors face price increases due to the gasoline tax indirectly. 


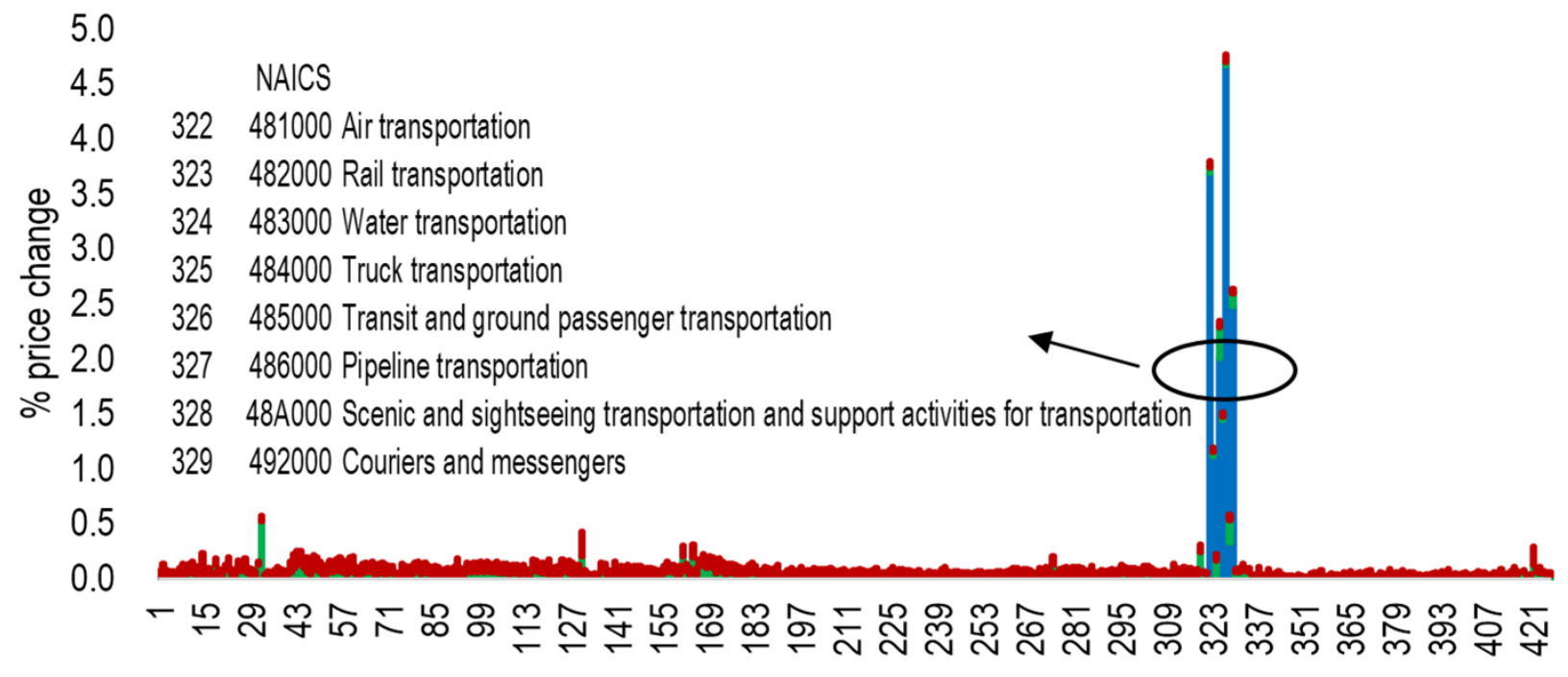

by tax $\square$ by direct supply $\square$ by indirect supply impact

Fig. 5. Percentage price change after 25 cent/gallon gasoline tax has been applied to the transportation sectors.

Price elasticities of demand are unit-free measures of responsiveness of quantity demanded $(Q)$ to changes in market prices $(p)$ - measured as the percentage change in quantity demanded for a given commodity, normalized by the percentage change in price as in Eq. (7). Price elasticity data is difficult to obtain for all commodities, but such information about some specific energy commodities is available from previous studies and historical data [41-44]. Price elasticity data utilized for this study can be found from a previous study [21]. Given the percentage price change obtained from the previous steps and the vector of price elasticities of demand for commodity, the vector of change in final demand can be estimated via Eq. (9). Fig. 6 illustrates the change in total production output from each industrial sector after the consumer demand decreased in response to the price increase of all commodities. It provides insight that all economic activities are intertwined, therefore, levying carbon price on the transportation sector decreases the economic activities of not only directly to the transportation sectors but also indirectly to all of the other economic sectors. 


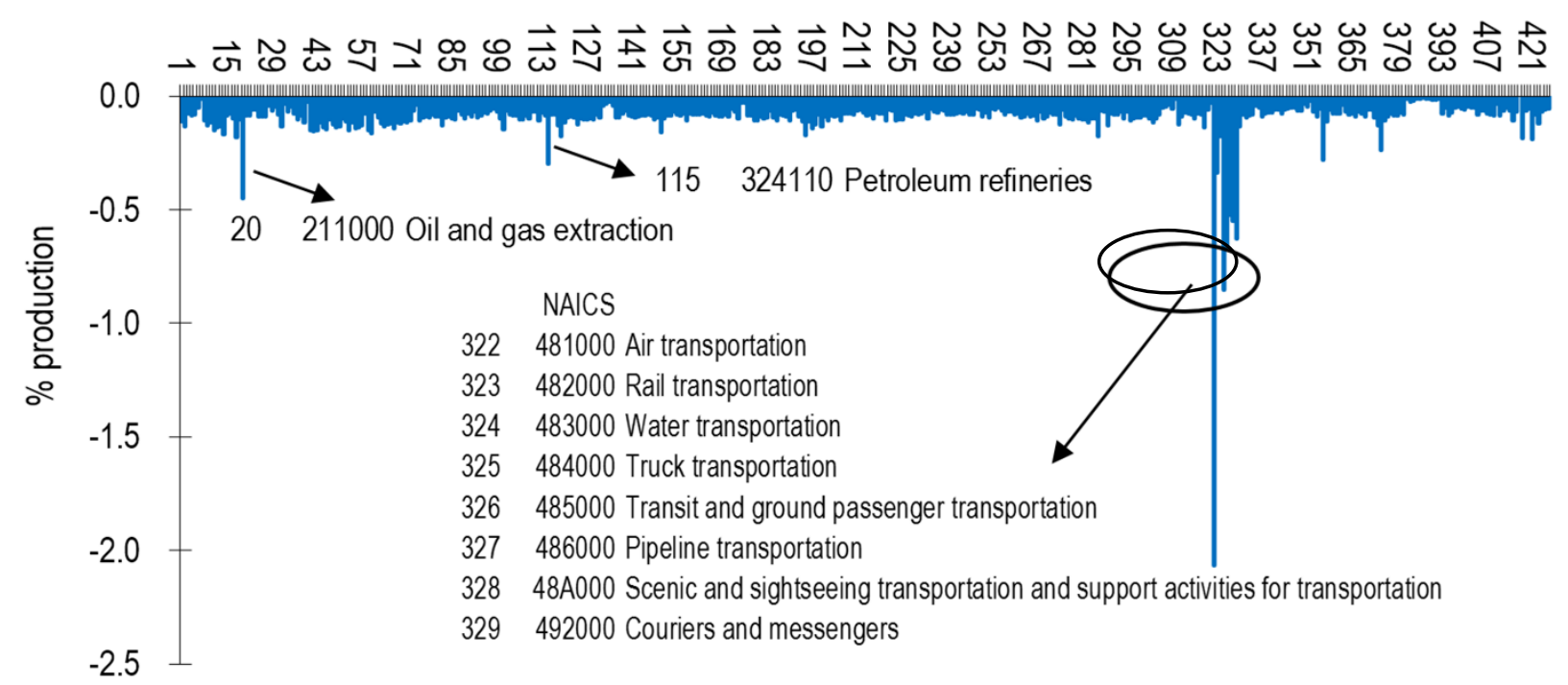

Fig. 6. Change of production after gas tax is applied to the transportation sectors

Fig. 7-(a) illustrates the percentile reduction of the consumption of some of the resources, ecosystem goods and services resulting from the decreased production of all economic sector's goods and services. Since all the economic activities are correlated, consumption of all the ecosystem services are reduced directly and indirectly. Crude oil consumption is decreased more than other ecosystem services because it is assumed that the consumption of transportation fuels decreases in respond to the price increase. This study only lists few examples of ecosystem services and resources, more comprehensive information can be found from the ECO-LCA website [1]. Fig. 7-(b) illustrates the economy-wide environmental emission changes after the carbon prices are levied to the transportation sectors. Although there are variations of changes for different emission, all of the emission are reduced in short term resulted from the decreased economic activities directly from the transportation sectors and other indirect economic sectors' activities.

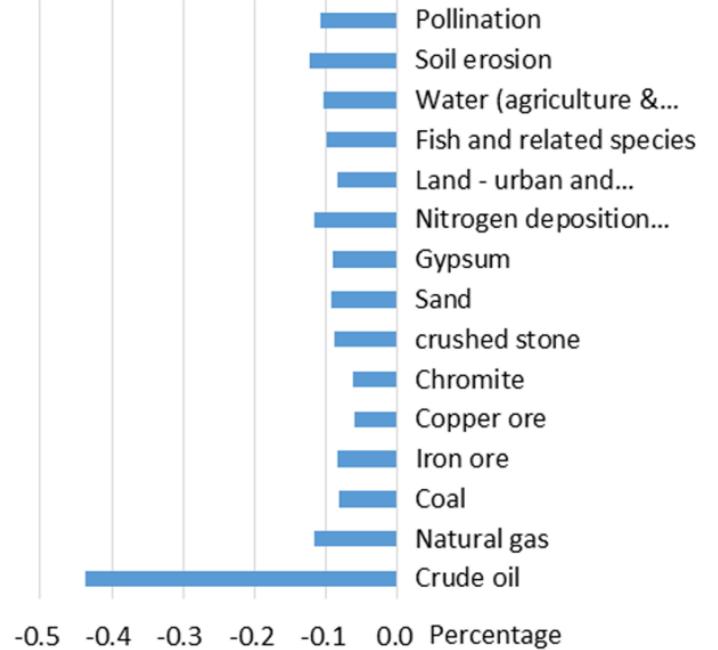

7-(a) resource /ecosystem goods and

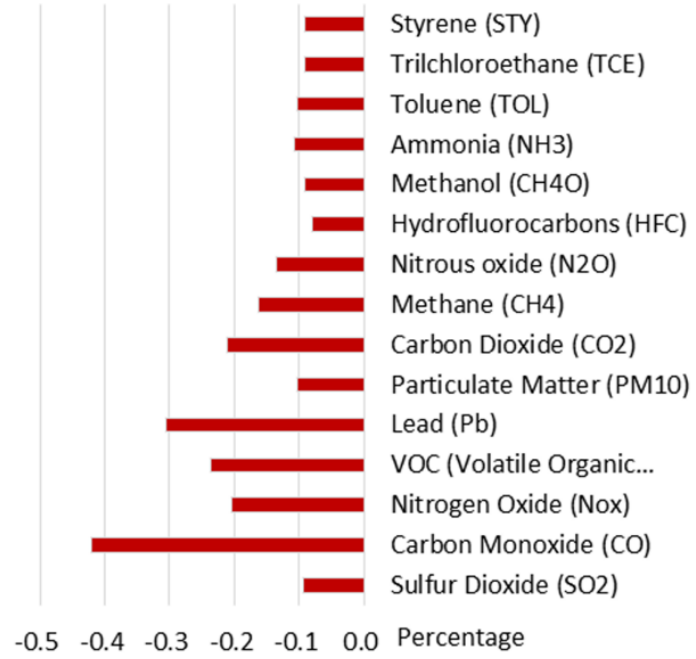

7-(b) emissions

Fig. 7. Changes after 25 cents per gallon gas tax is applied to the transportation sectors 


\subsection{Effect after the allocation of fuel tax revenues to subsidize biofuel production}

In 2009, U.S. capacity to generate the alternative fuel increased resulting from the government incentives designed to begin to reduce the country's dependence on oil imports. For example, under the U.S. Renewable Fuels Standard, refiners and fuel blenders are required to blend 10.5 billion gallons per year of traditional ethanol into gasoline [45]. As shown in the previous section, if $\$ 0.25 /$ gallon of hypothetical gas tax are levied through the economy, about $\$ 11.5$ billion dollars of tax revenues can be achieved. In this case study, we assume that certain percentage of this tax revenues can be invested to incentivize economic activities associated with the biofuel production. Currently, there are no direct economic sectors in the U.S. input-output table which disaggregates biofuel production out of food productions. Therefore, we have allocated these investment dollars (i.e. subsidies) to the value added row or the input output table proportional to the following economic sector's total production outputs: oilseed farming-1111A, grain farming-1111B, sugarcane and sugar beet farming-1119A, soybean and other oilseed processing-31122A, fats and oils refining and blending-311225, sugar cane mills and refining-31131A, beet sugar manufacturing -311313, distilleries -31214. It was out of the scope of this study to disaggregate the selected agricultural commodity sectors into biofuel production and food production because of the limited information. We tried to partially remedy this issue by assigning only $30 \%$ of the gas revenue to subsidize the biofuel production in the aggregated agricultural commodity sector, which is closest to a biofuel sector if we had a separate such sector. In terms of accounting for direct and indirect effects in the economy this is a justifiable approach to deal with the aggregation problem.

Fig. 8 shows the short-terms direct and indirect price decrease of economic goods and services after $30 \%$ of the gas tax revenues (i.e. $\$ 3.5$ billion dollars) are invested to subsidize the biofuel production. As mentioned, we selected arbitrary $30 \%$ of the gas tax revenues for investment. However, other specific percentage can be selected based on the target reduction on emissions, resource consumptions. As shown previously, economic activities for the production of cars, truck, airplane, gasoline fuels are directly and indirectly connected with diverse array of supply chain and manufacturing sectors. However, Fig. 8 shows that the major changes of commodity price are mostly concentrated in the food manufacturing sectors and various farming sectors after bio-subsidies are applied through whole economy. It implies the close supply chain relationship among the agricultural activities and the food productions in the existing input-output transactions.

We have assumed that the same price elasticity of demand utilized for capturing the demand response for the carbon price in the previous section. Given the percentage price change and the given vector of price elasticities, the vector of change in final demand can be estimated via Eq. (9). Fig. 9 illustrates the percentile increase of the total production from each industrial sectors after the consumer demand of some economic commodities increased in respond to the price decrease of those commodities. It shows the percentile increase of all commodities; direct increase by the potential biofuel production related sectors and cascading indirect increase of goods and services for all other economic sectors. As can be seen from the Fig. 9, even the economic production of the fertilizer manufacturing, pesticide and other agricultural chemical manufacturing products are increased because of the relatively strong supply chain relationship with the farming sectors. 


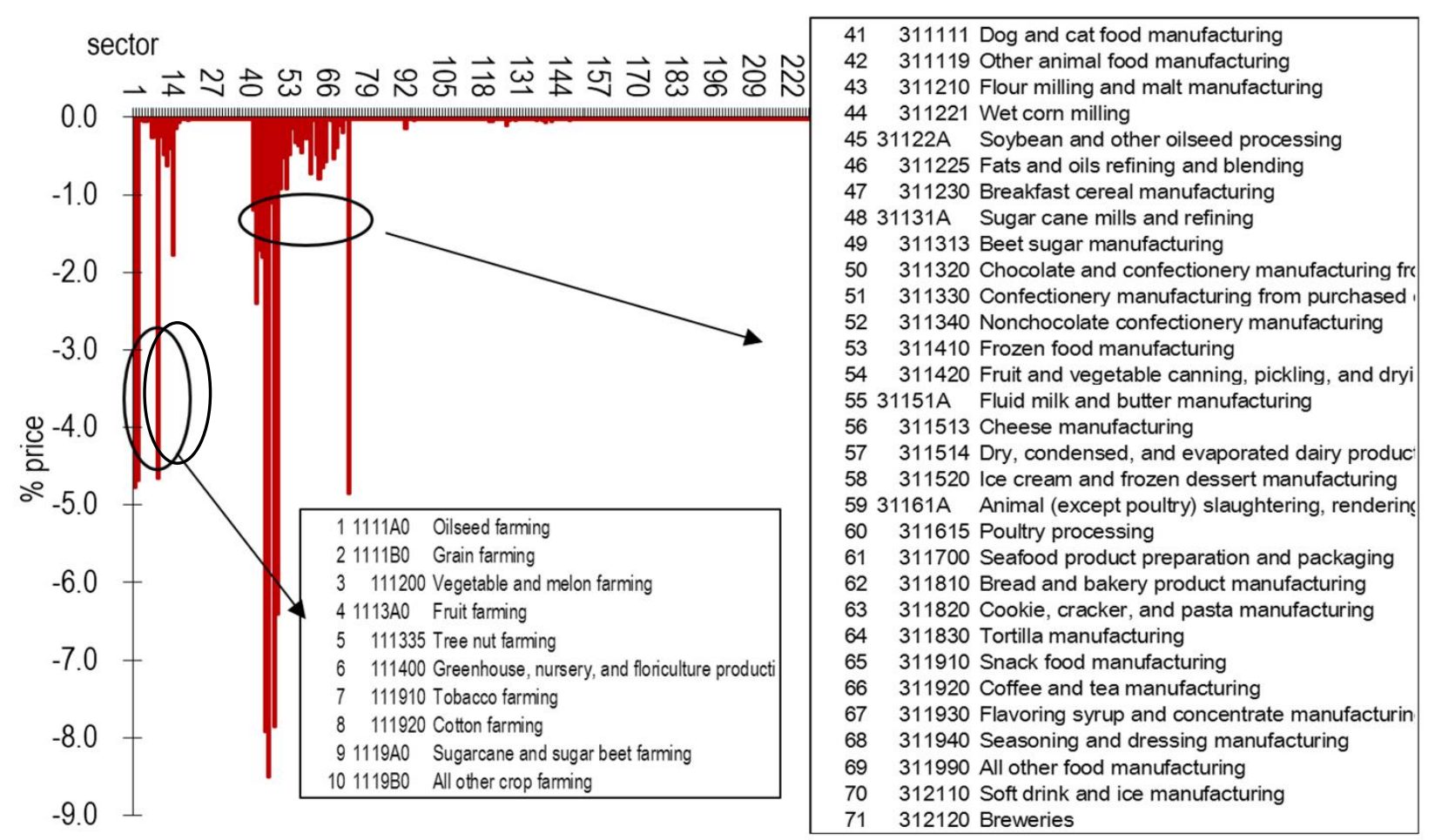

Fig. 8. Change of price after $30 \%$ of gas tax revenue is allocated to bio-fuel production related sectors.

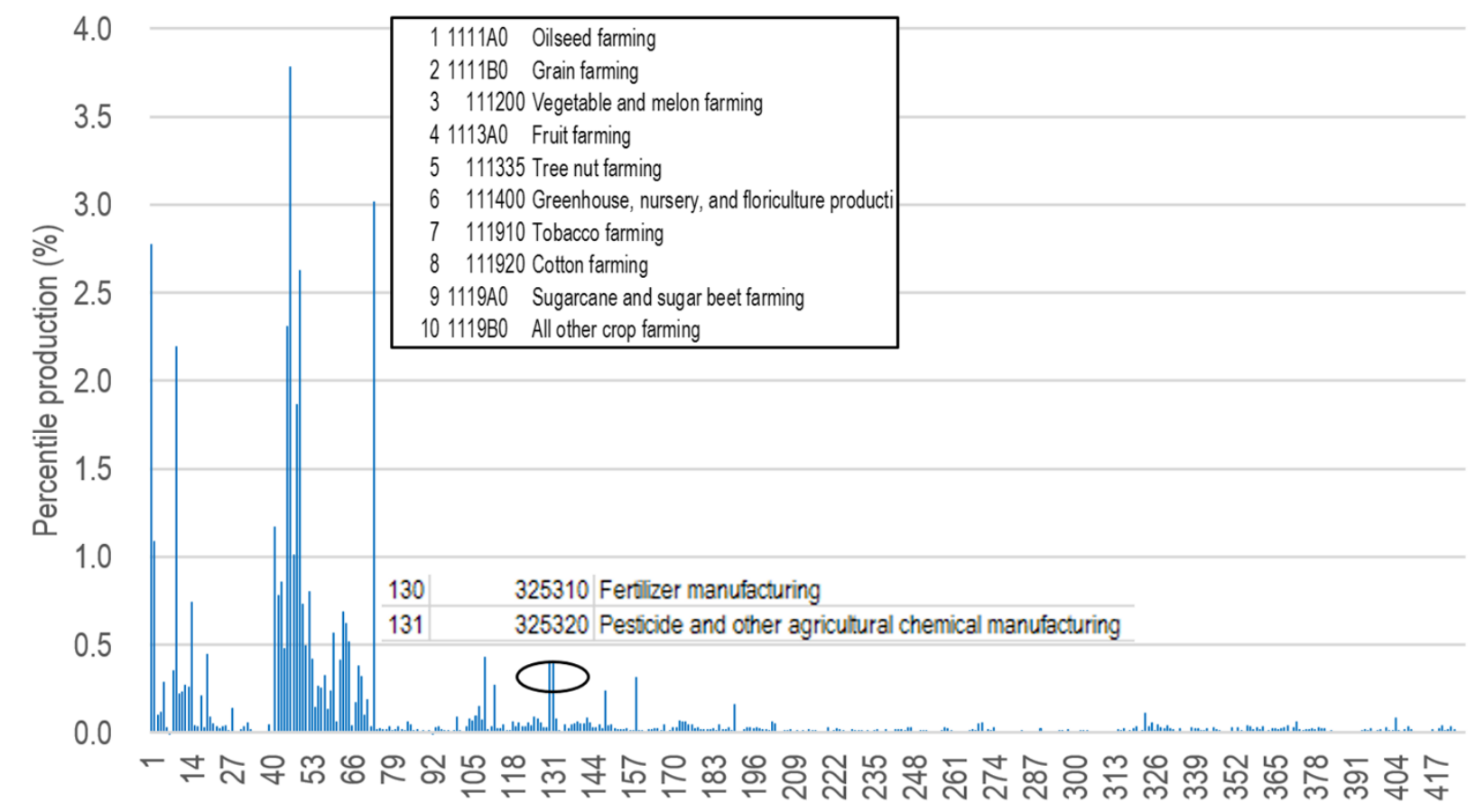

Fig. 9. Change of percentage production after $30 \%$ of gas tax revenue is allocated to biofuel production related sectors 
Fig. 10-(a) illustrates some examples of the increased consumptions of the resource and the ecosystem goods and services resulting from the increased production of all economic sector's goods and services. Since all the economic activities are correlated, consumption of all the ecosystem services are increased directly and indirectly. Especially, compared to the case of fuel tax, it shows that the subsidy for biofuels can have higher impacts on the resource consumption patterns and some ecosystem services related to farming activities (i.e. soil erosion from framing, water consumption for agricultural activities). Fig. 10-(b) illustrates economy-wide environmental emission changes after the bio-subsidies are provided to the relevant sectors. Although there are variations of changes for different emission, all of the emission are increased in short term resulted from the increased economic activities directly from the biofuel production related sectors and other indirect economic sectors' activities.

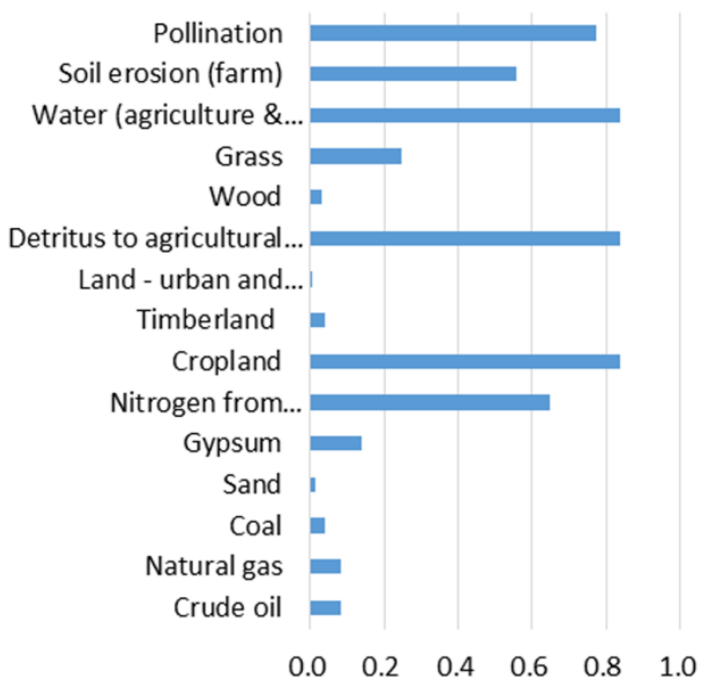

10-(a) resource/ecosystem goods and

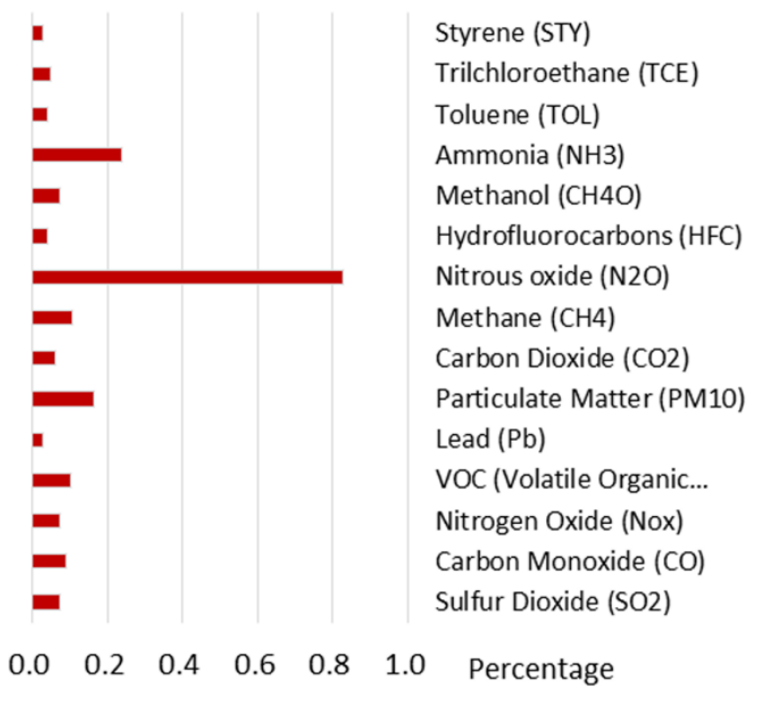

10-(b) emissions

Fig. 10. Changes after $30 \%$ of tax revenue is invested to bio-fuel production

\subsection{Change of environmental indicators after two subsequent policies}

Since the input-output tables in the proposed methodology adjust the monetary and physical transaction of commodities in each period after policy intervention, the physical amount of the environmental indicators in each period will not be affected by those perturbations. Therefore, resulting change of environmental loads after the fuel tax and the biofuel subsidies can be combined linearly. Figs. 11 (a) and 11 (b) shows the combined effect of two sequentially applied policies on the resource consumption and emission in the U.S. economy. It basically shows the relative importance and contribution of the resulting policies. Fig. 11-(a) illustrates that, with the given policy scenario (i.e. 25cents/gallon of fuel tax to whole economy plus 30\% reallocation of the tax revenue to the biofuel subsidy in the subsequent period), increases the ecosystem goods and services such as pollination, soil erosion, water consumption (for agriculture \& livestock), fish and related species, detritus to agricultural soil, crop land, nitrogen deposition whereas the scenario decreases 
economy-wide resource consumptions such as crude oil, natural gas, coal, iron ore, crushed stone, sand. Fig. 11-(b) illustrates the change of the total environmental emissions of the same scenario compare to the baseline period (i.e. before tax is applied). It shows that the nitrous oxide emission, ammonia, and PM 10 are increased while all other emissions are decreased. This kind of information can be utilized to design the optimal level of policy which considers the trade-off among the cost and benefit of economic and environmental impacts of policies. Policy maker can come into play with different number of tax and subsidy scenario to achieve specific target reduction of environmental indicator.

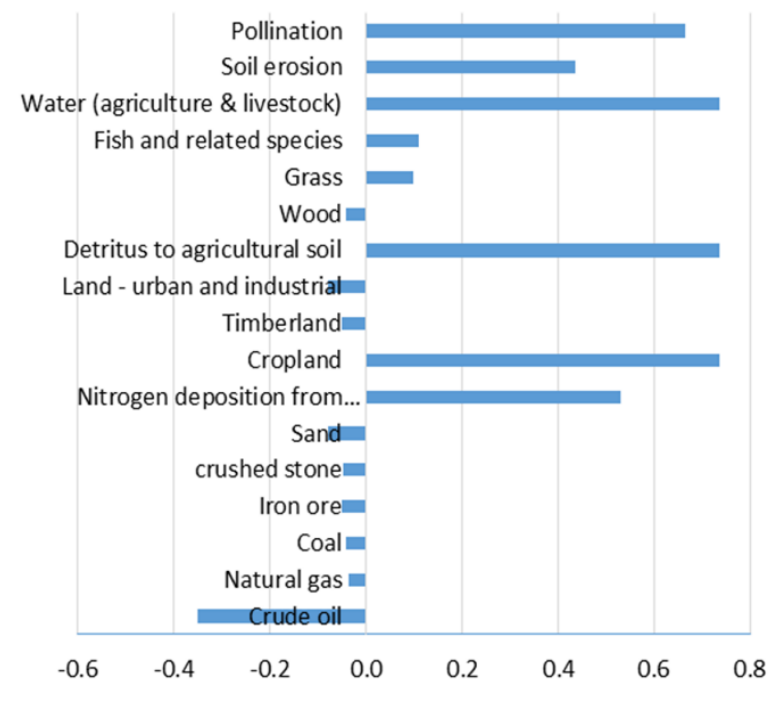

11-(a) resource/ecosystem services

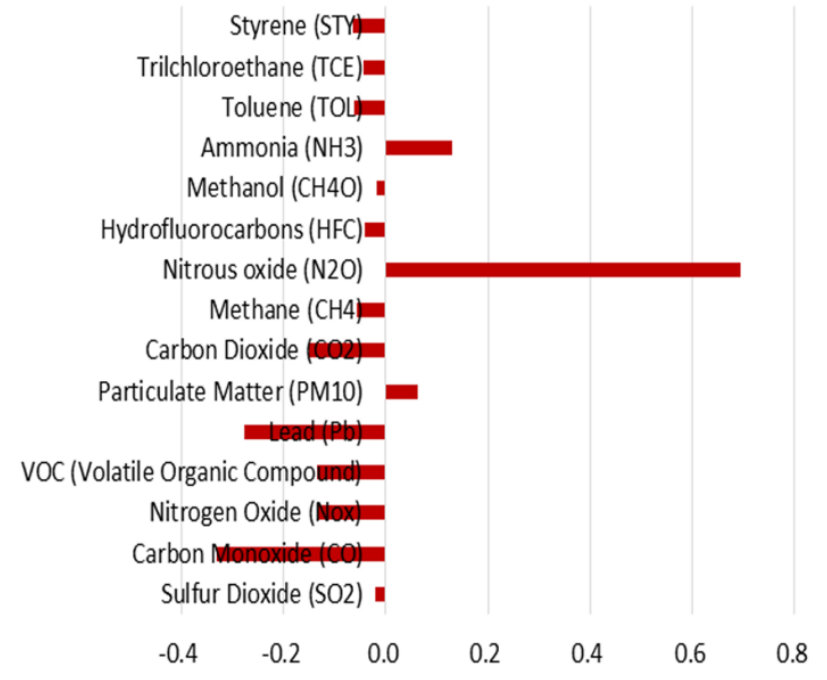

(b) emissions

Fig. 11. Changes after fuel tax plus bio subsidy combined subsequent policies

\section{Conclusions}

A general framework is developed for the analysis of economic impact through sequential input-output analysis. In monetary input-output tables, each monetary transaction among industries represents a combination of a physical quantity of a commodity and a corresponding price. These two distinct components of each monetary value are often utilized without careful consideration of the underlying components because of the following reasons: 1) aggregated monetary values are used, for example many monetary input-output studies analyze the variation of total monetary production of each sector caused by the variation of the final consumption expressed in the combined monetary value (i.e. price times quantity); 2) for single period input-output analysis, it is often considered as being not necessary to include the effect of price changes or the physical demand change corresponding to these price variations. However, if the effect of the price changes should be included in input-output analysis, there is a strong need for setting a systematic way of accounting for it. For example, if a carbon tax is levied, the price of all commodities changes directly and indirectly. Consumers can potentially adjust their consumption pattern and the entire economy ultimately gets affected. These kinds of analyses strongly require the consideration of the effect of price and the physical quantity variations in consecutive periods of analysis. In this paper, we propose a methodological 
framework which captures the variations of commodity prices and integrate it with the corresponding variation of the consumption pattern through a sequential input-output approach. We emphasize the importance of balancing the demand and the supply sides in the input-output table among the sequential periods of analysis. This framework can be utilized to study the economic and environmental effects of the intervention of various policies related to current issue of energy and environment.

In the short term, the gasoline tax can be an effective source of revenue since the demand for petroleum is relatively inelastic. However, in the long run, people may adjust their consumption pattern because of the price increases. Methods for adjusting the consumption include but not limited to switching to more fuel-efficient cars, mass transit, consolidating trips, carpooling, or just traveling less. However, whether the demand for petroleum is elastic or not in the long run is an empirical question, and the price elasticity of demand may change over time, for example, as new technologies and products which are substitutes and/or compliments become available. In this study, we do not consider these effects. Placing high taxes on fossil fuels makes alternative fuels more attractive, and put price pressure on manufacturers and consumers to choose more fuel-efficient products and processes. Proponents advocate that automobiles should pay for the roads they use and argue that the user tax should not be applied to mass transit projects. Critics argue transportation fuel taxes are a regressive tax, because low-income people pay a higher proportion with respect to their income, and transportation is not always an avoidable expense. These effects are not considered in our study either.

\section{Acknowledgments}

Authors appreciate the support from the University of Dayton's Research Council Seed Grant (Grant No. IGRQ14) and Hanley Sustainability Institute (Grant No. HIS-92024). Partial financial support from the National Science Foundation (ECS-0524924) is gratefully acknowledged. We acknowledge all reviewers for their great insight and comments for the paper.

\section{References}

[1] Ohio State University Center for Resilience. Ecologically-Based Life Cycle Assessment (Eco-LCA). 2012 <http://resilience.eng.ohio-state.edu/eco-lca>, [accessed 1/2016].

[2] Bakshi, B. and M.J. Small, Incorporating Ecosystem Services Into Life Cycle Assessment. Journal of Industrial Ecology, 2011. 15(4): p. 477-478.

[3] Baral, A. and B.R. Bakshi, Thermodynamic Metrics for Aggregation of Natural Resources in Life Cycle Analysis: Insight via Application to Some Transportation Fuels. Environmental Science \& Technology, 2010. 44(2): p. 800-807.

[4] Baral, A., B.R. Bakshi, and R.L. Smith, Assessing Resource Intensity and Renewability of Cellulosic Ethanol Technologies Using Eco-LCA. Environmental Science \& Technology, 2012. 46(4): p. 2436-2444.

[5] Millennium Ecosystem Assessment, Ecosystems and human well-being. Vol. 5. 2005: Island press Washington, DC:.

[6] Haines-Young, R. and M. Potschin, Common International Classification of Ecosystem Services (CICES, Version 4.1). European Environment Agency, 2012. 
<http://www.nottingham.ac.uk/cem/pdf/CICES\%20V43_Revised\%20Final_Report_ 29012013.pdf>, [accessed 3/2016]

[7] U.S. Department of Transportation. Federal Tax Rates on Motor Fuels and Lubricating Oil 2015 <http://www.fhwa.dot.gov/policyinformation/statistics/2014/fe101a.cfm>, [accessed 12/2015].

[8] U.S. Department of Transportation. State Motor-Fuel Tax Rates, 1999 - 2014. 2015 <http://www.fhwa.dot.gov/policyinformation/statistics/2014/mf205.cfm>, [accessed 12/2015].

[9] U.S. Energy Inofrmation Administration. How much carbon dioxide is produced by burning gasoline and diesel fuel? 2015 <https://www.eia.gov/tools/faqs/faq.cfm?id=307\&t=10>, [accessed 12/2015].

[10] Hammar, H., Åsa Löfgren, and Thomas Sterner, , Political Economy Obstacles to Fuel Taxation. The Energy Journal, 2004. 25(3): p. 1-17.

[11] Johansson, O. and L. Schipper, Measuring the Long-Run Fuel Demand of Cars: Separate Estimations of Vehicle Stock, Mean Fuel Intensity, and Mean Annual Driving Distance. Journal of Transport Economics and Policy, 1997. 31(3): p. 277-292.

[12] Cheng, Y.-H., Y.-H. Chang, and I.J. Lu, Urban transportation energy and carbon dioxide emission reduction strategies. Applied Energy, 2015. 157: p. 953-973.

[13] Sterner, T., Fuel taxes: An important instrument for climate policy. Energy Policy, 2007.35(6): p. 3194-3202.

[14] Searchinger, T., R. Heimlich, R.A. Houghton, F. Dong, A. Elobeid, J. Fabiosa, S. Tokgoz, D. Hayes, and T.-H. Yu, Use of U.S. Croplands for Biofuels Increases Greenhouse Gases Through Emissions from Land-Use Change. Science, 2008. 319(5867): p. 1238-1240.

[15] Delucchi, M.A., Impacts of biofuels on climate change, water use, and land use. Annals of the New York Academy of Sciences, 2010. 1195(1): p. 28-45.

[16] Michael, W., H. Jeongwoo, B.D. Jennifer, C. Hao, and E. Amgad, Well-to-wheels energy use and greenhouse gas emissions of ethanol from corn, sugarcane and cellulosic biomass for US use. Environmental Research Letters, 2012. 7(4): p. 045905.

[17] Wang, M.Q., J. Han, Z. Haq, W.E. Tyner, M. Wu, and A. Elgowainy, Energy and greenhouse gas emission effects of corn and cellulosic ethanol with technology improvements and land use changes. Biomass Bioenerg, 2011. 35.

[18] Dismukes, G.C., D. Carrieri, N. Bennette, G.M. Ananyev, and M.C. Posewitz, Aquatic phototrophs: efficient alternatives to land-based crops for biofuels. Current Opinion in Biotechnology, 2008. 19(3): p. 235-240.

[19] Leontief, W., Quantitative Input-Output Relations in the Economic System of the United States. Review of Economics and Statistics, 1986. 18(3): p. 105-125.

[20] Miller, R.E. and P.D. Blair, Input-Output Analysis: Foundations and Extensions. 1985, NJ: Prentice-Hall.

[21] Choi, J.-K., B.R. Bakshi, and T. Haab, Effects of a carbon price in the U.S. on economic sectors, resource use, and emissions: An input-output approach. Energy Policy, 2010. 38(7): p. 3527-3536.

[22] Cruz Jr, J.B., R.R. Tan, A.B. Culaba, and J.-A. Ballacillo, A dynamic input-output model for nascent bioenergy supply chains. Applied Energy, 2009. 86, Supplement 1(0): p. S86-S94. 
[23] Hondo, H., S. Sakai, and S. Tanno, Sensitivity analysis of total CO2 emission intensities estimated using an input-output table. Applied Energy, 2002. 72(3-4): p. 689-704.

[24] Chen, S. and B. Chen, Urban energy consumption: Different insights from energy flow analysis, input-output analysis and ecological network analysis. Applied Energy, 2015. 138(0): p. 99-107.

[25] Su, B. and B.W. Ang, Input-output analysis of CO2 emissions embodied in trade: A multi-region model for China. Applied Energy, 2014. 114(0): p. 377-384.

[26] Hubacek, K. and S. Giljum, Applying physical input-output analysis to estimate land appropriation (ecological footprints) of international trade activities. Ecological Economics, 2003. 44: p. 137-151.

[27] Hawkins, T., C. Hendrickson, C. Higgins, H.S. Matthews, and S.Suh, A mixed-unit inputoutput model for environmentla life-cycle assessment and material flow analysis. Environ. Sci. Technol., 2007. 41: p. 1024-1031.

[28] Bullard, C. and R. Herendeen, The Energy Costs of Goods and Services. Energy Policy, 1975. 1(4): p. 268-277.

[29] Dietzenbacher, E. and J. Stage, Mixing oil and water? Using hybrid input-output tables in a Structural decomposition analysis. Economic Systems Research, 2006. 18(1): p. 85-95.

[30] Albino, V., E. Dietzenbacher, and S. Kuhtz, Analysing Materials and Energy Flows in an Industrial District using an Enterprise Input-Output Model. Economic Systems Research, 2003. 15(4): p. 457-480.

[31] Oosterhaven, J., Leontief versus Ghoshian Price and Quantity Models. Southern Economic Journal, 1996. 62(3): p. 750-759.

[32] Giljum, S. and K. Hubacek, Alternative Approaches of Physical Input-Output Analysis to Estimate Primary Material Inputs of Production and Consumption Activities. Economic Systems Research, 2004. 16(3): p. 301-310.

[33] United Nations, UN Handbook on Supply, Use and Input-Outpu Tables, in Compiling Physical Supply and Use Tables (PSUTs) and Environmentally Extended Input-Output Tables (EE-IOTS), S. Mahajan, Editor. 2015, United Nations: United Nations Statistics Divisions.

[34] Leontief, W., Input-Output Economics. 2 ed. 1986, Oxford: Oxford University Press.

[35] Trefler, D., International Factor Price Differences: Leontief was Right! Journal of Political Economy, 1993. 101(6): p. 961-987.

[36] Leontief, W., Environmental repercussions and the economic structure: an inputoutput approach. The review of economics and statistics, 1970: p. 262-271.

[37] Choi, J.-K., D. Morrison, K.P. Hallinan, and R.J. Brecha, Economic and environmental impacts of community-based residential building energy efficiency investment. Energy, 2014. 78: p. 877-886.

[38] Choi, J.-K., K. Hallinan, K. Kissock, and R. Brecha. Economic and Environmental Impacts of Energy Efficiency Investment on Local Manufacturers. in ASME 2015 International Design Engineering Technical Conferences and Computers and Information in Engineering Conference. 2015. American Society of Mechanical Engineers.

[39] Choi, J.-K., P. Friley, and T. Alfstad, Implications of energy policy on a product system's dynamic life-cycle environmental impact: Survey and model. Renewable and Sustainable Energy Reviews, 2012. 16(7): p. 4744-4752. 
[40] American Petroleum Institute. State Gasoline Tax Reports. 2015 $<$ http://www.api.org/Oil-and-Natural-Gas-Overview/Industry-Economics/FuelTaxes>, [accessed 12/2015].

[41] Goodwin, P., J. Dargay, and M. Hanly, Elasticities of road traffic and fuel consumption with respect to price and income: A review. Transport Reviews, 2004. 24(3): p. 275292.

[42] Espey, M., Explaining the variation in elasticity estimates of gasoline demand in the United States: A Meta-Analysis. Energy Journal, 1996. 17(3): p. 49-60.

[43] Hughes, J.E., C.R. Knittel, and D. Sperling, Evidence of a shift in the short-run price elasticity of gasoline demand. 2006, Institute of Transportation Studies: University of California, Davis.

[44] Spees, K. and L.B. Lave, Demand Response and Electricity Market Efficiency, in Carnegie Mellon Electricity Industry Center Working Paper CEIC-07-01.2007, Carnegie Mellon University.

[45] Schnepf, R. and B.D. Yacobucci. Renewable Fuel Standard (RFS): overview and issues. in CRS Report for Congress. 2010. 